International Journal of Behavioral Research \& Psychology (IJBRP)

ISSN 2332-3000

\title{
A Comparison of Working And Non-Working Women In Terms of Self-Differentiation, Partner Abuse, Conflict Resolution Tactics, Marital Satisfaction And Quality of Life
}

Review Article

Barahmand $\mathrm{U}^{*}$, Nafs A N

Associate Professor, Affiliation: University f Mohaghegh Ardabili, Iran.

\begin{abstract}
Aim: The purpose of the study was to compare working and nonworking women with regard to self-differentiation, partner abuse, conflict resolution tactics and the association of these variables with marital satisfaction and quality of life.

Method: Using specific inclusion criteria, a sample of 160 women ( 80 working, and 80 non-working women) were recruited for the study. Data were collected using The Differentiation of Self Inventory-Revised, Partner Abuse Scale-Physical, The Revised Conflict Tactics Scales, Miller Social Intimacy Scale, The Revised Dyadic Adjustment Scale, The Comprehensive Marital Satisfaction Scale and the WHO Quality of Life Scale. Data were analyzed using descriptive statistics, multivariate analysis of variance, Pearson's correlation coefficients and multiple regression analysis.

Results: Findings revealed significant group differences, with working women reporting greater intimacy, adjustment, marital satisfaction and better quality of life and non-working women reporting greater partner abuse, and the use of psychological aggression, physical assault and physical injury to resolve conflicts. Results of regression analysis indicated that emotional cut-off, a component of self-differentiation, accounted for $42.2 \%$ and $16.9 \%$ of the variance in quality of life among working and non-working women respectively. Among non-working women, physical assault as a conflict resolution tactic accounted for an additional 33\% of the variance in quality of life. Findings point to significant differences between working and non-working women. A significant finding was that most women in both groups reported poor adjustment with their spouses, although working women tended to report greater intimacy.
\end{abstract}

Conclusions: It can be concluded that, working women enjoy better quality of life than non-working women who tend to experience greater partner abuse.

Key Words: Self-Differentiation; Partner Abuse; Conflict Tactics; Marital Satisfaction; Quality Of Life.

\section{*Corresponding Author:}

Usha Barahmand,

Associate Professor, University f Mohaghegh Ardabili, Iran.

Tel: +989144519649

E-mail: usha.barahmand@gmail.com

Received: October 18, 2013

Accepted: November 20, 2013

Published: November 22, 2013

Citation: Barahmand U, Nafs A N (2013) A Comparison Of Working And Non-Working Women In Terms Of Self-Differentiation, Partner Abuse, Conflict Resolution Tactics, Marital Satisfaction And Quality Of Life. Int J Behav Res Psychol. 1(2), 5-11.

doi: http://dx.doi.org/10.19070/2332-3000-130002

Copyright: Usha Barahmand ${ }^{\circ} 2013$. This is an open-access article distributed under the terms of the Creative Commons Attribution License, which permits unrestricted use, distribution and reproduction in any medium, provided the original author and source are credited..

\section{Introduction}

Following the World Health Organization's definition of health as physical, mental and social well-being, more number of researchers go beyond attending to the absence of symptoms in their assessments of health and recovery from diseases. One of concepts introduced in this context and a focus of much research, is quality of life. Quality of life is a holistic construct that views human health and well-being within the contexts of proximal and distal environments (Lindstrom, 1992). The World Health Organization defines quality of life as individuals' perceptions of their position in life in the context of the culture and value systems in which they live and in relation to their goals, standards, and concerns (WHOQOL Work Group 1998, p. 551). The latter definition includes perceptions of overall quality of life, individuals' experiences and values, and has included related, proxy indicators such as well-being, happiness and life satisfaction. Models of quality of life are also not consistent, ranging from needs based approaches derived from Mallow's (1968) hierarchy of human needs (deficiency needs: hunger, thirst, loneliness, security; and growth needs: learning, mastery and self-actualization), to classic models based solely on psychological well-being, happiness, morale, life satisfaction (Andrews, 1986; Andrews and Withey, 1976; Larson, 1978), social expectations (Calman, 1983) or the individual's unique perceptions (O.Boyle 1997). Quality of life is thus a complex collection of interacting objective and subjective dimensions (Lawton 1991).

In their efforts to determine factors associated with people's quality of life, researchers have revealed that the family and the interaction styles between its members is one prominent dimension relating to people's quality of life, happiness and well-being in all 
cultures. Studies have accumulated strong evidence showing that family life affects happiness greatly (Rodgers \& Bachman, 1988). Chilman (1982) reviewed major national surveys from 1957 to the end of the 1970s and concluded that even though societal views of marriage and family have undergone dramatic and fundamental transformations, family life is still widely seen as central to life satisfaction and happiness; furthermore, married people have an advantage, on indices of anxiety and unhappiness, over those who are single, divorced or separated (Lu \& Lin, 1998).

Low quality of life and marital discord frequently co-occur, particularly among women. Previous studies have revealed that marital discord is an important risk factor for depression among many married people (Beach, Sandeen, \& O'Leary, 1990). Although Beach, Sandeen and O'leary (1990) in their marital discord model of depression recognize that the etiology of depression is often multifaceted, but they argue that the decreased social support and increased hostility in troubled relationships can precipitate depressive symptomotology. In their study on psychosocial variables associated with depression, Brown and Harris (1978) found that the lack of a confiding relationship is a vulnerability factor in the development of depression in women. Specifically, the variable low intimacy with husband was associated with depression in women. In 1987, Weissman reported that individuals in unhappy marriages are 25 times more likely than those in happy marriages to be diagnosed with clinical depression. In their study examining the role of humiliating marital events, such as husband infidelity or threat of marital dissolution on the wife's depressive symptoms, Cano and O'Leary (2000) found that after controlling for levels of marital discord, women who had experienced such severe marital stressors were six times more likely to be diagnosed with a Major Depressive Episode. These findings remained even after controlling for lifetime and family histories of depression. Depressed individuals in unhappy marriages also recover less quickly from a depressive episode (e.g., McLean, Ogston, \& Grauer, 1973), and are more likely to experience a relapse of their depressive symptoms (Fiedler, Backenstra $\beta$, Kronmüller, \& Mundt, 1998). Whisman (2001) found that marital dissatisfaction accounted for approximately $18 \%$ of the variance of wives depressive symptoms and 14\% of husbands' depressive symptoms. Gabriel and Beach (2010) found that marital interaction behavior depends on gender, depression and marital distress. Waite, Lue and Lewin (2009) found general support for this hypothesis that emotional well-being tends to decline following marital disruption, across a range of dimensions of well-being. Darvizeh and Kahki (2008) reported that there are correlations between marital satisfaction and well-being in married female college students.

In regard to physical health, stressful marital interactions are associated with lower physical activity (Schwartz et al., 1994). Empirical examination indicates that marital quality and satisfaction are positively related to measures of global health (Hetherington, 1993), as well as indices of better immune (antibody titers to various viral agents; Kiecolt-Glaser et al., 1988) and cardiovascular system functioning (Ewart, Taylor, Kraemer, \& Agras, 1991). Furthermore, a decline in marital satisfaction is associated with a decline in the self-reported health of both partners (Levenson \& Gottman, 1985). Lastly, marital satisfaction is related to pronounced cardiovascular reactivity during conflict, such that unhappily married individuals display faster heart rates and greater elevations in blood pressure than happily married individuals (Ewart et al., 1991; Whitson \& El-Sheikh, 2003).

Results of Giannouli et al (2012) showed that higher total QoL in women was predicted by being married, physical exercise and a good financial status. In this study, women with a better QoL were more health conscious and more likely to have utilized the public health preventive resources.

In recent decades, the number of working women has increased in developed and developing countries-which includes Iran- and, there has been a concomitant increase in the number of divorced couples. In the absence of information regarding the mechanisms underlying the relationship between women's employment and marital instability, no causal relationship between women's employment and divorce can be inferred. However, through an exploration of the many variables related to marital satisfaction and quality of life, the likely relationship between women's employment and marital instability can be understood.

Marital dissatisfaction refers to a couple's evaluation of their relationship and does not include the presence or absence of thoughts or actions associated with the breakup of a marriage. To our knowledge, the mechanisms by which women's employment influences the quality of marital relationship have not been studied. In an attempt to identify the underlying mechanisms, some theories and studies have focused on self-differentiation, spouse abuse, conflict resolution, intimacy, and adjustment. The building blocks of the self are innate, but the familial interactions of individuals during childhood and adolescence determine the boundaries of self-development.

People with a poorly differentiated "self" depend so heavily on the acceptance and approval of others that either they quickly adjust what they think, say, and do to please others or they dogmatically proclaim what others should be like and pressure them to conform. Individuals with a well-differentiated self have realistic awareness about their dependence on others, but can stay calm in situations such as conflict, criticism or rejection, and are able to think clearly and evaluate facts accurately without being affected by emotions. Such individuals acquire proper principles for making decisions about crucial family and social issues and rarely give in to their instinctive emotions. Self-differentiation in a marital relationship can be described as follows:

1. The ability to feel responsible while feeling committed towards the partner.

2. Tendency to self expression (self disclosure)

3. Keeping contact whilst having tension and disagreement

4. The ability to clearly state one's needs and to ask others for help without imposing one's needs on others

Partner abuse refers to an individual's attempts to control their partner by any means in marital relationship so that even intimidation and stalking are kinds of spouse abuse. Physical violence includes any sort of attack that varies from pushing, pinching, strangling, stabbing, shooting and murder. Psychological harassment can be verbal and emotional. Sexual harassment is any behavior that includes using sex to control or humiliate the victim. Economic or financial harassment includes actions that limit freedom and financial security. Intimidation and stalking are any threatening and repetitive behaviors, including unannounced presence at home or the work place, making annoying phone calls, sending annoying messages or limiting the victim's access to money. Partner abuse is a major issue in general health as millions suffer from it and often end up with physical and emotional disorders and even death. 
Some factors related to partner abuse have been defined, which are related to a marital relationship such as conflicts or marital dissatisfaction, patriarchy in the family, financial pressures, considerable differences in the educational levels of the couple, where the wife's educational status is higher than her husband's, and husband's inclination to engage in promiscuous sexual relationships.

Couples report different sources of conflict that vary from verbal and physical attack to personal characteristics and behavior. Disagreement between partners regarding the division of labor bears a relationship with marital conflict. Conflict about power has also been found to be related to marital dissatisfaction. Conflict resolution can be both positive and negative: positive resolution improves the interactions between partners while negative resolution ruins their interactions since it accompanies criticism of personality and revenge and conflict over power (Marchanow and Hawlk, 2000).

Dyadic adjustment is defined as consensus, affectional expression, friendship, participation in common activities and cohesion. Some researchers (Kilbourn, Hable and England, 1993) found that couples who engage in activities together in their leisure express more marital satisfaction. Understanding and consensus are common characteristics in partners that determine marital compatibility.

Prager (1995) suggested a multi-component definition of intimacy that includes many aspects of the present definitions. Prager believes that intimacy has both behavioral and emotional components; the behavioral component includes actions such as touching and speaking and the emotional component includes the feeling of love and togetherness. The relationship between intimacy and marital satisfaction has not been clearly identified. Researchers have come to a consensus that there is a relationship between intimacy and marital satisfaction.

Grant and et al., (1990) consider quality of life as an individual's statement of the positive and negative aspects of their life. Quality of life is an abstract concept affected by various factors such as physical, mental and social conditions. Many studies have shown that factors determining quality of life are physical conditions, marital quality and family life. (Shaq, 1995; Bourman and Markosen, 1992).

In Iran, an increase in women's employment outside the home has occurred during the last few decades, especially in urban areas. Today, as more and more women are entering the work force, a parallel change in the Iranian culture as regards the role and expectations of women is taking place. A working woman may face difficulties in attempting to fulfill the demands she faces both at home and in the workplace, while a housewife may feel tired and irritated with her household chores and financial dependence. Both groups of women strive for increasing independence, marital satisfaction and better quality of life while they deal with everyday hassles and interpersonal conflicts. The present study compares a group of working mothers with their non-working counterparts with respect to:
a. self-differentiation
b. partner abuse
c. conflict resolution tactics
d. marital quality and
e. quality of life.

In as much as women's health and well-being are important factors related to family health and ultimately society's health, the findings of this research can provide insight into the factors that contribute to marital adjustment and quality of life in working and non-working women. Findings can also aid marriage counselors in providing informed guidance to women who seek to improve their marital relations as well as the quality of their life.

\section{Method}

\section{Participants}

A sample of 160 married women (80 working and 80 non-working women) was recruited for the study. Only women who were at least 20 years old, with at least 8 years of schooling, and had been married for at least 3 years were included in the study. Those being treated for physical and mental problems were excluded from the study.

Women working in schools, universities, and government offices were invited to participate in the study. After obtaining consent, the questionnaires were administered to the study sample. The non-working women were selected from among women who were conveniently accessibly.

\section{Measures}

\section{- Sociodemographic data sheet}

A sociodemographic data sheet was constructed by the authors to collect information regarding the age, educational status, occupation, number of children, duration of marriage, presence of physical and mental disorders.

\section{- The differentiation of self inventory-revised (DSI-R;} Skowron \& Friedlander, 1998; Skowron \& Schmitt, 2003)

The DSI-R is a 46-item self-report measure that focuses on adults, their significant relationships, and current relations with family of origin. Participants rate items using a 6-point Likert-type scale, ranging from 1 (not at all true of me) to 6 (very true of me). The DSI contains four subscales: ER, EC, IP, and Fusion with Others (FO). The ER scale assesses the tendency to respond to environmental stimuli on the basis of autonomic emotional responses, emotional flooding, or emotional lability. The IP scale contains items that reflect a clearly defined sense of self and the ability to thoughtfully adhere to one's convictions even when pressured to do otherwise. The EC scale consists of items reflecting fears of intimacy or engulfment in relationships, and the accompanying behavioral defenses against those fears. The FO scale reflects emotional over-involvement with significant others and overidentification with one's parents - taking in parental values, beliefs and expectations without question. Subscale scores are calculated by reversing raw scores on all items on the ER, EC, and FO subscales and one item on the IP subscale. Scores on all items are then summed across a subscale and then divided by the number of items on the subscale, such that scores on each subscale also range from 1 to 6 , with high scores reflecting greater differentiation of self, specifically, less ER, EC, and FO, and more skill in taking IP in relationships. Internal consistency reliabilities of the DSI-R and its subscales reported by Skowron and Schmitt (2003) 
were good: DSI full scale .92, ER, .89, IP.81, EC .82, and FO .85.

\section{- Partner Abuse Scale-Physical (PASPH)}

This questionnaire is designed to measure the non-physical abuse experienced in relationship with a partner. The PASPH consists of 25 items designed to measure the degree of physical abuse a person receives from her spouse. Participants respond to each item using a 7-point scale ranging from 1 (none of the time) to 7 (all of the time). The PASPH is scored by summing the scores, subtracting the number of completed items, multiplying this figure by 100 , and dividing by the number of items completed times 6. This produces a range from 0 to 100 with higher scores indicating greater severity of problems.

\section{- The Revised Conflict Tactics Scales (CTS2)}

The revised Conflict Tactics Scales (CTS2) is the most widely used instrument for measuring intimate partner violence. The CTS2 (Straus et al., 1996) is a 78-item self-reporting instrument that measures the extent of prevalence and chronicity in four areas of intimate partner violence (Psychological Aggression, Physical Assault, Sexual Coercion, and Injury) as well as the extent of positive tactics (Negotiation) in dealing with a dating, cohabiting, or marital conflicts. The Negotiation scale consists of two subscales representing cognitively and emotionally based items, and the other four scales measuring violence are further broken down into the minor and severe forms of violence. All the scale items are formulated in pairs; among the 78 items, half of the items address what the respondent has done to his/her partner (perpetration) and the other half address what the partner has done to the respondent (victimization). The present study used one groups of 39 items to reflect the victimization facets of the CTS2. Respondents rate an individual item on an 8-point scale: 1 (1 time in past year), 2 (2 times in past year), 3 (3-5 times in past year), 4 (6-10 times in past year), 5 (11-20 times in past year), 6 (more than 20 times in past year), 7 (not in the past year but it did happen before), and 0 (this has never happened). This produces "Self" and "Partner" scores for each of the dimensions.

\section{- Miller Social Intimacy Scale (MSIS)}

The 17-item Miller Social Intimacy Scale (Miller \& Lefcourt, 1982) was designed to assess intimacy in adult relationships. The measure consists of 6 items that measure the frequency of intimate contacts and 11 items that assess the intensity of intimate relations. Each of the items are rated on 10-point scales, ranging from 1 (very rarely or not much) to 10 (almost always or a great deal). Higher scores indicate more intimacy in relationships. Psychometric properties of the scale are strong and suggest that it is a reliable and valid measure of social intimacy (Downs \& Hillje, 1991; Miller \& Lefcourt, 1982).

The MSIS is designed to assess intimacy in a variety of relationships (e.g., friendships, family, spouse), although these categories have not yet been examined with sexual offenders. Therefore, for the purpose of the present study, all participants completed the MSIS four times, describing typical relationships with (a) male friends, (b) female friends, (c) family members, and (d) a spouse/ significant other.

\section{- The Revised Dyadic Adjustment Scale (RDAS)}

The revised dyadic adjustment scale (RDAS) has been widely used as an indicator of the quality of marital relationship. This scale was developed by Busby et al.The original version was developed by Spanier in 1976. According to his theory about quality of marital relationship. Bradbury, Fincham and Beach introduced this scale for assessing quality of marital relationship. This 14item questionnaire was developed using 32 items ofthe original form which was invented by Spanier and include Likert scale. This questionnaire includes three subscales which are collaboration, consensus, satisfaction and coherence that totally show marital adjustment. Higher scores indicate better marital adjustment. The Cronbach's alpha coefficients in previous studies have been reported from 0.80 to $0.90(29)$.In the current study the reliability in the preliminary sample $(\mathrm{N}=35)$ was 0.79 .

\section{- The Comprehensive Marital Satisfaction Scale (CMSS)}

The Comprehensive Marital Satisfaction Scale uses 35 statements to gauge each spouse's perception of their relationship, general satisfaction, and interpersonal interaction. These statements were answered on a scale of -4 (very strong disagreement) through 0 (neutral) and up to +4 (very strong agreement). The CMSS has confirmed content validity and construct validity. The test-retest reliability for the CMSS was found to be .83 over a six-week interval and its alpha internal consistency coefficient was 0.94 (Mehrabian, 2005).

\section{- World Health Organisation Quality of Life Assessment - Short Version (WHOQOL-BREF)}

The World Health Organisation Quality of Life AssessmentBref has 26 items and measures four broad domains: physical health, psychological health, social relationships and environment. Moreover, it includes one facet covering overall QoL and general health. The items are rated on a 5-point Likert scale. A higher score indicates better quality of life. The WHOQOL-Bref domain scores show good discriminant validity (physical health, psychological health, social relationships, and environment), content validity, internal consistency (Cronbach alpha: physical health 0.80 , psychological health 0.76 , social relationships 0.66 and environment 0.80) and test-retest reliability (WHOQOL Group, 1998; Skevington et al., 2004a).

\section{Data analysis}

Data were analyzed using descriptive and inferential statistics. Group differences were evaluated using multivariate analysis of variance (MANOVA) and the contribution of each variable in the prediction of the quality of life of working and non-working women was determined by multivariate regression analysis.

\section{Results}

The descriptive statistics are displayed in Table 1 and the group differences are displayed in Tables 2. The associations between self-differentiation, partner abuse and conflict resolution tactics with quality of life of working and non-working women are presented in Table 3. Finally, Tables 4 and 5 show the contribution of each variable in the prediction of quality of life in the two groups.

\section{Discussion and Conclusions}

The purpose of this research was to compare working and nonworking women in terms of self-differentiation, spouse abuse, conflict resolution and marital quality. Results of the present re- 
Table 1. The percentage of individuals in each group reporting high levels of self-differentiation and partner abuse, and low levels of intimacy, dyadic adjustment, marital satisfaction and quality of life

\begin{tabular}{|l|l|l|l|}
\hline \multicolumn{1}{|c|}{ Variables } & Level & \multicolumn{2}{|l|}{ Percentage within groups } \\
\hline & & Working & Non-working \\
\hline Self-differentiation & High & 10 & 8 \\
\hline Partner abuse & High & 0 & 0 \\
\hline Intimacy & Low & 3.8 & 3 \\
\hline Dyadic Adjustment & Low & 100 & 100 \\
\hline Marital satisfaction & Low & 5 & 15 \\
\hline Quality of Life & Low & 13.8 & 16.3 \\
\hline
\end{tabular}

Table 2. Group means and standard deviations with results of the MANOVA for the variables under study

\begin{tabular}{|c|c|c|c|c|c|}
\hline Variables & Subscales & Group & Mean & Std. Deviation & $\mathbf{F}$ \\
\hline \multirow[t]{10}{*}{ Self-differentiation } & Emotional reactivity & Working & 31.88 & 7.14 & 2.61 \\
\hline & & Non-working & 33.9 & 8.52 & \\
\hline & I Position & Working & 40.01 & 4.8 & $24.73^{* *}$ \\
\hline & & Non-working & 36.32 & 4.56 & \\
\hline & Emotional cut-off & Working & 20.73 & 6.19 & $8.32 * *$ \\
\hline & & Non-working & 23.6 & 6.35 & \\
\hline & Fusion with others & Working & 29.15 & 6.35 & 2.96 \\
\hline & & Non-working & 27.41 & 6.42 & \\
\hline & Total & Working & 121.78 & 14.38 & 0.04 \\
\hline & & Non-working & 121.23 & 16.86 & \\
\hline \multirow[t]{2}{*}{ Partner abuse } & & Working & 25.35 & 1.3 & $15.81 * *$ \\
\hline & & Non-working & 27.4 & 4.42 & \\
\hline \multirow[t]{10}{*}{ Conflict Tactics } & Negative negotiation & Working & 6.56 & 0.88 & 3.26 \\
\hline & & Non-working & 6.32 & 0.77 & \\
\hline & Psychological aggression & Working & 14.12 & 1.85 & $11.22 * *$ \\
\hline & & Non-working & 13.06 & 2.14 & \\
\hline & Physical assault & Working & 23.52 & 0.72 & $5.53 *$ \\
\hline & & Non-working & 23.13 & 1.28 & \\
\hline & Sexual coercion & Working & 13.98 & 0.11 & 0 \\
\hline & & Non-working & 13.98 & 0.11 & \\
\hline & Injury & Working & 11.95 & 0.35 & $7.68^{* *}$ \\
\hline & & Non-working & 11.63 & 0.94 & \\
\hline \multirow[t]{2}{*}{ Intimacy } & & Working & 151.73 & 11.05 & $16.11^{* *}$ \\
\hline & & Non-working & 144.22 & 12.56 & \\
\hline \multirow[t]{2}{*}{ Dyadic adjustment } & & Working & 38.6 & 3.98 & $20.42^{* *}$ \\
\hline & & Non-working & 35.56 & 4.49 & \\
\hline \multirow[t]{2}{*}{ Marital Satisfaction } & & Working & 257.55 & 32.17 & $19.21 * *$ \\
\hline & & Non-working & 232.87 & 38.72 & \\
\hline \multirow[t]{2}{*}{ Quality of Life } & & Working & 4.6 & 0.24 & $75.76^{* *}$ \\
\hline & & Non-working & 4.22 & 0.3 & \\
\hline
\end{tabular}

*difference is significant at the .05 level

$* *$ difference is significant at the .01 level

search show that employed women report higher self-differentiation. In other words, compared to unemployed women, employed women are more self-reliant. They are able to function independently without anxiety and dependence on others. Having high self differentiation means that in conditions of conflict, criticism or rejection, the individual can evaluate accurately and can discriminate facts from beliefs clouded with emotions. The finding that unemployed women have lower self-differentiation shows that they are highly dependent on others. As regards the components of self-differentiation, I-position and fusion with oth- ers, employed women scored higher but on the emotional cut-off subscale, the unemployed women scored higher. On the whole, findings indicate that employed women report more independence, more emotional intimacy with their partner and greater selfdifferentiation.

Unemployed women also tended to report greater spouse abuse than their unemployed counterparts. Unemployed women reported utilizing more psychological strategies, physical assault, injury and harassment. In other words, unemployed women tended to 
Table 3. Correlations between self-differentiation, partner abuse, conflict resolution tactics, and quality of life in working and non-working women

\begin{tabular}{|l|l|l|l|}
\hline \multicolumn{1}{|c|}{ Variables } & \multicolumn{1}{|c|}{ Subscales } & \multicolumn{2}{c|}{ Quality of life } \\
\hline & & \multicolumn{1}{c|}{ Working women } & Non-working women \\
\hline Self-differentiation & Emotional reactivity & $-.422^{* *}$ & -0.057 \\
\hline & I position & $.417 * *$ & 0.067 \\
\hline & Emotional cut-off & $-.642^{* *}$ & $-.411^{* *}$ \\
\hline & Fusion with others & $-.339^{* *}$ & 0.092 \\
\hline Partner abuse & Total & $-.497 * *$ & -0.13 \\
\hline Conflict Resolution tactics & & $-.253^{*}$ & $-.312^{* *}$ \\
\hline & Negative negotiation & -0.153 & -0.076 \\
\hline & Psychological aggression & 0.081 & $.358^{* *}$ \\
\hline & Physical assault & 0.005 & $.312^{* *}$ \\
\hline & Sexual coercion & -0.041 & -0.046 \\
\hline & Injury & $.230^{*}$ & $.363^{* *}$ \\
\hline
\end{tabular}

*Correlation is significant at the .05 level

** Correlation is significant at the .01 level

Table 4: Summary of Hierarchical Regression Analysis for Variables Predicting Working women's Quality of life

\begin{tabular}{|c|c|c|c|c|c|c|c|}
\hline & \multirow[b]{2}{*}{$\mathbf{R}^{2}$} & \multirow[b]{2}{*}{$\Delta \mathbf{R}^{2}$} & \multirow[b]{2}{*}{$\mathbf{F}$} & \multicolumn{2}{|c|}{ Unstandardized Coefficients } & \multirow{2}{*}{$\begin{array}{c}\text { Standardized Coefficients } \\
\text { Beta } \\
\end{array}$} & \multirow[t]{2}{*}{$\mathbf{t}$} \\
\hline & & & & B & Std. Error & & \\
\hline (Constant) & & & & 4.751 & 2.183 & & 2.176 \\
\hline Emotional reactivity & 0.178 & 0.178 & 16.91 & 0 & 0.004 & -0.005 & -0.039 \\
\hline I-position & 0.231 & 0.053 & 5.31 & 0.006 & 0.006 & 0.125 & 1.146 \\
\hline Emotional cut-off & 0.422 & 0.191 & 25.13 & -0.024 & 0.005 & -0.598 & $-4.898^{* *}$ \\
\hline Fusion with others & 0.429 & 0.006 & 0.81 & 0.003 & 0.005 & 0.081 & 0.688 \\
\hline Partner abuse & 0.442 & 0.014 & 1.81 & -0.016 & 0.033 & -0.083 & -0.484 \\
\hline Injury & 0.443 & 0.001 & 0.08 & 0.034 & 0.117 & 0.048 & 0.289 \\
\hline
\end{tabular}

$*$ Contribution significant at .05 level

** Contribution significant at .01 level

Table 5: Summary of Hierarchical Regression Analysis for Variables Predicting Working women's Quality of life

\begin{tabular}{|c|c|c|c|c|c|c|c|}
\hline & \multirow[b]{2}{*}{$\mathbf{R}^{2}$} & \multirow[b]{2}{*}{$\Delta \mathbf{R}^{2}$} & \multirow[b]{2}{*}{$\mathbf{F}$} & \multicolumn{2}{|c|}{ Unstandardized Coefficients } & \multirow{2}{*}{$\begin{array}{c}\text { Standardized Coefficients } \\
\text { Beta } \\
\end{array}$} & \multirow{2}{*}{$\mathbf{t}$} \\
\hline & & & & B & Std. Error & & \\
\hline (Constant) & & & & 3.371 & .780 & & 4.321 \\
\hline Emotional cut-off & .169 & .169 & 15.87 & -.015 & .005 & -.310 & $-3.068^{* *}$ \\
\hline Partner abuse & .216 & .047 & 4.64 & -.014 & .009 & -.207 & -1.541 \\
\hline Psychological aggression & .292 & .076 & 8.10 & .025 & .016 & .176 & 1.603 \\
\hline Physical assault & .330 & .038 & 4.26 & .052 & .026 & .217 & $1.96^{*}$ \\
\hline Injury & .330 & .000 & .018 & .006 & .046 & .019 & .135 \\
\hline Injury & 0.443 & 0.001 & 0.08 & 0.034 & 0.117 & 0.048 & 0.289 \\
\hline
\end{tabular}

$*$ Contribution is significant at .05 level

** Contribution is significant at .01 level

use strategies such as yelling, insulting, accusing and destroying objects.

The quality of marital relationship in this study is reflected by four variables: intimacy, dyadic adjustment, marital satisfaction and quality of life. All these variables were evaluated in both groups of employed and unemployed women. Findings show that employed women reported more intimacy, more marital satisfaction, greater understanding and consensus, more company and adjustment with their partners and, in general, reported better quality of life. Reports of marital satisfaction and better quality of life by employed women are likely on account of greater intimacy, understanding, consensus, cohesion and, in general, better adjustment among them. Various factors such as women's educational status and that of their partners, their financial status, self-differentiation and conflict resolution tactics may have contributed to differences in these groups. The results of regression analysis show that in both groups of employed and unemployed women, self-differentiation can predict intimacy, adjustment, satisfaction and quality of life. Employed and unemployed women tended to report higher intimacy and adjustment with their partners and greater marital satisfaction and quality of life. 
Findings of this research show that married women have lower self-differentiation, experience marital satisfaction and better quality of life. It appears that in the Iranian culture, being submissive and dependent on the husband is considered a value. Conflict resolution plays a role in intimacy, adjustment, marital satisfaction and quality of life in both groups of employed and unemployed women. In both groups there was an inverse relationship between the utilization of the strategy of psychological aggression, as well as intimacy, adjustment, marital satisfaction and quality of life. There was also a relationship between physical assault, and intimacy, adjustment, satisfaction and quality of life in the group of employed women. Both groups of women mentioned utilizing psychological aggression which probably resulted in reduced intimacy, adjustment, satisfaction and quality of life.

\section{References}

[1]. Blum, J.S., \& Mehrabian, A. (1999). Personality and temperament correlates of marital satisfaction. Journal of Personality, 67, 93-125.

[2]. Booth, A.C. Crouter, \& M. Clements (Eds.), Couples in conflict (pp. 5981). Mahwah, NJ: Erlbaum.

[3]. Bradbury, T. N.(Ed).(1998) The developmental course of marital dysfunction.New York:Cambridge University Press.

[4]. Bradbury, T.N., Fincham, F.D., \& Beach, S.R.H. 2000. Research on the nature and determinants of marital satisfaction: A decade in review. Journal of Marriage and the Family, 62, 964-980

[5]. Bradbury, T.N., Rogge, R., \& Lawrence, E. (2001). Reconsidering the role of conflict in marriage. In A.

[6]. Busby, D.M., Crane, D.R., Larson, J.H., \& Christensen, C. (1995). A revision of the Dyadic Adjustment Scale for use with distressed and nondistressed couples: Construction hierarchy and multidimensional scales. Journal of Marital and Family Therapy, 21, 289-308.

[7]. Corcoran, K., \& Fischer, J. (2000). Measures for clinical practice: A sour- cebook

[8]. Elizabeth A., Skowron and Myrna L. Friedlander .1998. University at Albany, State University of New York. Journal of Counseling Psychology Vol. 45, No. 3, 235-246.

[9]. Fincham F. D., \& Kashdan, T. B. (in press). Facilitating forgiveness. In P. A. Linley \& S. Joseph (Eds.), International handbook of positive psychology in practice: From research to application.

[10]. Fincham, F. D. (2000). Optimism and the family. In J. Gillham (Ed.), The science of optimism and hope (pp. 271-298). Philadelphia: Templeton Press.

[11]. Fincham, F. D. (2000). The kiss of the porcupines: From attributing responsibility to forgiving. Personal Relationships, 7, 1-23.

[12]. Fincham, F. D., \& Beach, S. R. H. (1999). Conflict in marriage: Implications for working with couples. Annual Review of Psychology, 50, 47-77.

[13]. Fincham, F. D., \& Bradbury, T. N. (1987). The assessment of marital quality: A reevaluation. Journal of Marriage and the Family, 49, 797-809.

[14]. Fincham, F. D., Beach, S. R., \& Kemp-Fincham, S. I. (1997). Marital quality: A new theoretical perspective. In R. J. Sternberg \& M. Hojjat (Eds.), Satisfaction in close relationships (pp. 275-304). New York: Guilford Press.

[15]. Garcia-Moreno C et al. WHO multi-country study on women's health and domestic violence against women: initial results on prevalence, health outcomes and women's responses. Geneva: World Health Organization, 2005.

[16]. Gottman, J. And Silver, N. (1999). The Seven Principles for Making Marriage Work. (p. 6-47). New York: Three Rivers Press.

[17]. Gray, J. A. (1987). The psychology of fear and stress. Cambridge, England: Cambridge University Press.

[18]. Ko Ling Chan. Sexual violence against women and children in Chinese societies. Trauma, Violence \& Abuse, 2009, 10(1):69-85.

[19]. Miller, R. S., \& Lefcourt, H. M. (1982). The assessment of social intimacy. Journal of Personality Assessment, 46(5), 514-518.

[20]. Roberts,L.J(2000) Fire and ice in marital communication ,Hostile and distancing behaviors as predictors of marital distress.Journal of Marriage and The Family,62,693-707.

[21]. Straus, M. A., Hamby, S. L.., McCoy, S. B., \& Sugarman, D. B. (1996). The Revised Conflict Tactics Scales (CTSZ) Journal of Family Issues. Vol. 17 No. 3. May 1996 283-316

[22]. Usefy, A. R., Ghassemi, Gh., R., Sarrafzadegan, N., Mallik, S., Baghaei, A. M. \& Rabiei, M. (2010). Psychometric Properties of the WHOQOLBREF in an Iranian Adult Sample Community Mental Health Journal, DOI $10.1007 /$ s10597-009-9282-8 